\title{
EVOLUTION OF DOWNHOLE MEASUREMENT SYSTEMS
}

\author{
Peter Lysne \\ Geoscience Research Driiling Office \\ Sandia National Laboratories \\ Albuquerque, NM 87185
}

\begin{abstract}
An often-cited example of the need for technology development arises from the lack of downhole tools suitable for use in thermal regimes. But a more general reason for development stems from the nature of scientific drilling in that work is conducted in regions of the Earth's crust that differ from the sedimentary regions of interest to the traditional logging industry. Thus, even well-established tools must be examined for data integrity and information content. Interactions between scientific drilling programs and industrial institutions can further this mission at a time when budgetary difficulties are manifest. These interactions will require guarantees that evolutionary systems are useful and practical; guidelines addressing such quality issues are under development within the Ocean Drilling Program.
\end{abstract}

\section{INTRODUCTION}

Thrusts in the geosciences are placing an ever-increasing demand on downhole measurement systems at a time when the potential for major strides forward are possible, but when contributions from the previously supportive hydrocarbon industry are almost non-existent.

The majority of downhole measurements used in scientific programs originated in the hydrocarbon industry where advances proceeded in a hand-over-hand fashion. The first documented measurements were made in 1927 when the Schlumberger brothers demonstrated that resistivity measurements could be used to make hole-to-hole correlations. Later, resistivity measurements were rendered quantitative when an empirical relation was established between the resistivity and porosity. Since porosity is of strategic importance, "Archie's Law" provided justification for the development of better downhole tools in the form of focused-electrode devices. But the resulting measurements revealed difficulties with Archie's interpretation, so shaley-sand models evolved. In turn, these models required input concerning clay content, and this need drove refinements in nuclear logging tools. This process of need-derived advancement continued until the severe depression of the hydrocarbon industry began in the early 1980 s. Relatively few advances in downhule measurements have occurred in the past decade even though technological achievements make progress imminently feasible.

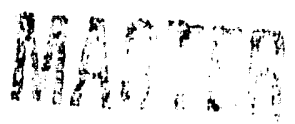




\section{DISCLAIMER}

This report was prepared as an account of work sponsored by an agency of the United States Government. Neither the United States Government nor any agency Thereof, nor any of their employees, makes any warranty, express or implied, or assumes any legal liability or responsibility for the accuracy, completeness, or usefulness of any information, apparatus, product, or process disclosed, or represents that its use would not infringe privately owned rights. Reference herein to any specific commercial product, process, or service by trade name, trademark, manufacturer, or otherwise does not necessarily constitute or imply its endorsement, recommendation, or favoring by the United States Government or any agency thereof. The views and opinions of authors expressed herein do not necessarily state or reflect those of the United States Government or any agency thereof. 


\section{DISCLAIMER}

Portions of this document may be illegible in electronic image products. Images are produced from the best available original document. 
A transition in scientitic thinking and energy-development strategies also oceurred in the early 1980s. During this time, the Deep Sea Drilling Program was reborn as the Ocean Drilling Program, and strong continental drilling programs emerged in several countries. These programs moved away from the sedimentary basins of importance to the hydrocarbon industry, and soon it became apparent that common downhole tools and interpretive techniques were in need of modification. Concurrently, drilling into thermal regimes was initiated in the geothermal industry, and this drilling was advanced by several scientific endeavors. Unfortunately, the loose federation of geothermal and scientific interests was insufficient to sustain a hrust aimed at development of high-temperature tools. In fact, some advances made in the early 1980s have heen lost due to an entrenchment of the high-temperature semiconductor industry. It is now apparent that funding constraints on scientific and industrial fronts are a major hurdle to understanding crustal matters, and that strong cooperative efforts must be initiated if momentum is to be gained.

The purpose of this paper is to assess downhole measurements as they pertain to scientific programs, and to note where collaborative efforts may be initiated. First, generic issues of tool response to formation and borehole conditions are addressed because they apply to all measurement systems. The paper then deals with the particular case of high-temperature tools because such tools are evolving in scientific and industrial programs. The next section puts forth the need for rules governing the development of measurement systems, and presents the set of governing conditions that were recently adopted by the Ocean Drilling Program. Finally, a view to the future is made.

\section{GENERIC ISSUES}

From the viewpoint of a logging specialist, physical properties fall into two categories: (1) primary properties that can be readily determined downhole, and (2) secondary properties that are of importance, but are difficult to measure directly using downhole instruments. The primary properties include quantities such as borehole shape, teluperature, resistivity, scnic velocity, hydrogen content, and density. These properties often delineate quantities or features of interest, and they are used in hole-to-hole correlation. Furthermore, resistivity, sonic velocity, and density are necessary to calibrate surface geophysical studies. Secondary properties include porosity, permeability, lithology, oxidation state, and water saturation. These quantities may be determined from core, but core may not be available if drilling conditions are bad, if industry holes of opportunity are exploited for scientific purposes, or if budgetary constraints are overriding.

Foundations for the measurement of primary properties are based on the defining equations of classical physics, on a knowledge of proper boundary conditions for the solution of the ensuing partial differential equations, and on a model for the material properties of the media surrounding the sonde. The material model contains one or more adjustable parameters that represent quantities of the first category. The adjustable parameters are obtained ahrough routines that fit measured quantities (voltages, time 
differences, count rates, etc.) to the model. To illustrate these concepts, appropriate relations for four tools commonly used to determine porosity are listed in Table 1 . Due to the importance of porosity to the hydrocarbon industry, resistivity, sonic, neutron, and gamma tools have received considerable attention in recent years. A cogent discussion of these and other tools has been published (Hearst and Nelson, 1985); a review of techniques used in scientific programs is also available (ODP, 1990).

The relevance of the material model plays an important role in evaluating a tool's response. For example, the response of a resistivity tool is based on Ohm's Law, a linear relation between the electric field and the current density. This material model is proper as long as the formation is isotropic and homogeneous on a scale that is large compared to characteristic volumes introduced in the solution of the differential equations that govern the tool's response. Similarly, the neutron tool used to measure hydrogen content is accurate as long as the porosity, the water saturation, and the amount of material with large thermal neutron absorption properties is constant within each characteristic volume. Such information is hest obtained from core, although complete core is not needed. This situation illustrates that core and logs are complementary systems, and they should be used together to provide information at a minimum cost.

In the past, the solution of the differential equations governing a tool's response was tedious and often inexact due to the large characteristic volumes and symmetry constraints introduced to make the problem tractable. Thus, tools were calibrated in test pits designed to simulate the range of subsurface conditions that they were expected to encounter. This approach leads to the "dolomite", "limestone", or "sandstone" calibrations that are applicable to clean sediments, but of uncertain applicability to other materials.

Recently, fast computers using modern finite-element and Monte Carlo algorithms have mitigated the modeling problem since both very small characteristic volumes and three-dimensional geometries are tractable. Now the cost of evaluating a tool is far less than that encountered when test pits were a necessity, and the effect of subtle variations in the material models can be thoroughly explored provided knowledge of the interior workings of the tool are available. Unfortunately, some logging companies treat ihis information as proprietary. If cooperative companies cannot be found, re-development of an existing tool concept may be justified to insure a better understanding of important measurements.

Consider now the relations between primary and secondary properties. In principle, these relations are governed by basic physics, and appropriate relations could be found by following paths similar to those discussed above. However, geometrical issues are very complex and occur on a size commensurate with pore dimensions. Even the best computational techniques cannot solve such detailed problems. Perhaps statistical techniques will provide solutions. For the present, a major difficulty arises because correlations between primary and secondary properties are uncertain and ambiguous. 
Table 1 lists relations that have been used to tie primary properties to porosity. The ambiguity in these relations is emphasized by the over fifty variations of Archie's Law that have evolved over the years (a skeptic might note that Archie's law is a linear fit on a log-log plot that implies no theoretical justification). Clearly, there is a need for a better fundamental understanding of relations between primary and secondary properties, and advances in the understanding of these relations will have a profound effect on both scientific and applied endeavors.

\section{HIGH-TEMPERATURE TOOLS}

The issues that confront the geothermal industry present an illustration of the points raised in the previous section. An often-cited obstacle to downhole measurements in hot holes is that available tools are physically incompatible with the geothermal environment, and the cost of developing and maintaining a suitable tool suite exceeds the anticipated revenues from logging services. Since a service industry can only be supported if measurements produce output useful to its clients, and since interpretative techniques developed for hydrocarbon reservoirs are not proven in geothermal formations, a second obstacle is the general inability to relate log data to useful information. In some respects, the development of a viable geothermal logging industry is impeded by the chicken-egg syndrome. Scienific drilling programs can help overcome this impasse.

Hostile environment tools commonly found in the logging service industry are capable of operation up to $260^{\circ} \mathrm{C}$ so they are applicable to some, but not all, hightemperature formations. Furthermore, size constraints are imposed by the diamond coring techniques that are commonly used in scientific and geothermal exploration programs. Taken together, the temperature and the tool diameter provide criteria for the design of logging equipment. Given present needs and realistic technologies, a modern tool will be operable at the critical point of sea water $\left(407^{\circ} \mathrm{C}, 289.5 \mathrm{bar}\right)$, and it will be less than $50 \mathrm{~mm}$ in diameter so that it will fit through an " $\mathrm{H}$ " size coring bit and into an "N" size hole.

Conceptually, two classes of tools are able to meet these criteria. The first class utilizes a teflon $\left(300^{\circ} \mathrm{C}\right.$ maximum) or magnesium-oxide-insulated electrical wireline to transmit power and data between the tool and the surface. The second class is completely self-contained in that power is obtained from batterits, and uata are stored in a memory system. Even though memory tools have been around for decades, they have not found common usage due to past limitations. This situation is changing rapidly due to improvements in digital technology.

Both classes of tools were used to make high-resolution temperature measurements in the VC-2B scientific corehole to $295^{\circ} \mathrm{C}$, see Figure 1 , and the results of this work had a major effect on the directions of tool development in the United States. While data were of equivalent quality, the tool using a teflon-insulated electric wireline failed about one-half of the time due to wireline or cable-head difficulties. Significantly, the memory tool has never experienced a data loss. This record includes 
the fathful recording of temperature excursions during fishing exercises made when the tool was twice dropped through $2.5 \mathrm{~km}$ of internal upset drill pipe. The suceess rate, and the relatively low cost of memory tools has prompted the US Department of Energy and other US institutions to make a major thrust in their development.

While memory tools are inexpensive, logging scientists raise the issue that the memory concept is flawed by the lack of communication between the tool and the operator. The greatest concern is that a tool will fail, yet the logging run continue due to lack of information. Perhaps future tools will possess some means of communicating a failed condition to the surfice. In any event, memory tools must possess reliability and quality to be credible.

In the same vein, logging strategies are often evolved on the basis of real-time data. Memory tools preclude this approach. This point is not as valid now as it was in the past since modern data-logging systems support languages that are "intelligent". Thus, a logging strategy that contains contingencies may be programmed into the tool. Finally, the power available in a battery operated tool is limited. This means that powerintensive measurements are constrained to short duration. Examples of instruments currently under development within the world community are: a precision pressure/temperature tool, a spectral gamma tool, a fluid sampler, a focused resistivity tool, and a fluid conductivity tool.

\section{ODP GUIDELINES FOR SYSTEM DEVELOPMENT}

The Orean Drilling Program (ODP) and associated institutions have maintained a modest effort in tool development for nearly a decade. While a few tools have been successful and have moved on into the industrial sector, many have languished due to an underestimation of the development difficulty and cost. Furthermore, engineering deficiencies in these "Third-Party" tools have resulted in inordinate expenditures of ship's time for a limited data return. Thus, the ODP has adopted a set of guidelines for tool development (ODP, 1992).

A feature of the ODP plan is that a Principal Investigator must be identified, and that this individual is the primary proponent for the development and use of the tool. Among other issues, this investigator must submit a plan that identifies development milestones, that makes provisions for land testing, that specifies the usefulness of the proposed measurements, and that contains a statement that the tool would be available for post-development deployment in the ODP. It is most important to note that Principal Investigator is tasked with leading the development of a measurement system, not just a to)l.

An ODP tool development program follows a prescribed course consisting of three stages. A Developmem Tool is either a tool that is under development externally for use in the ODP or a tool that has been developed outside the ODP for other purposes, and is being considered for ODP deployment. Unlike tools in more advanced stages of development, the scientific success of a cruise cannot depend on a Development Tool. 
After the development stage, the tool attains the status of a Certified Tool, and it may be an integral part of a scientific endeavor. The request for certification includes cost estimates for routine operation including data processing, details concerning spare parts, operating and maintenance manuals, and a demonstration of the usefulness of the datia. A certified $(0)$ remains under the purview of the Principal Investigator.

Finally, a Mature Tool is an established tool that has hecome part of the ODP tool suite. Such a tool is effectively owned by the ODP.

The ODP guidelines for $t(x)$ d development are new and evolving. The tasks that are placed on the Principal Investigator are difficult, and require strong support from numerous scientific and engineering disciplines. This support will be costly. But the programmatic consequences of failed efforts are much more costly since failures stifle scientific innovation. It is not clear how the ODP will muster the necessary resources to support evolutionary efforts; it is clear that strong scientific rationale is necessary to justify their existence. The ODP, working through the entire JOIDES Panel structure, is forming a consensus regarding the evolution of downhole measurement systems. The resulting model will form the basis for a more general technology-development thrust that will influence all areas of the geological sciences.

\section{CONCLUDING REMARKS}

There is a clear need for new downhole measurement tools and interpretation techniques within the various scientific drilling programs. Furthermore, this need extends into institutions that are recovering resources from the crust, or using the crust as a repository for wastes. The depressed condition of the hydrocarbon industry precludes the strong advances that this sector offered to the science of downhole measurements in the past. However, the prevailing economic condition means that doors will be open for cooperation between the scientific and industrial institutions. It is proper and necessary for the scientific community to initiate cooperative ventures.

\section{ACKNOWLEDGMENT}

This work was supported by the US Department of Energy/Office of Basic Energy Sciences/Geoscience at Sandia National Laboratory under contract DE-AC(0476DP(0)789. 


\section{REFERENCES}

Hearst, Joseph R., and Philip H. Nelson, 1985. "Well Logging for Physical Properties", McGraw-Hill Book Company.

Lysne, Peter, 1991. "Pressure, Volume, Temperature States within the VC-2B Corehole, Valles Caldera, New Mexico, USA", Applied Geochemistry, Vol. 6, pp. 665-670.

ODP, 1990. "Wireline Logging Manual", available from the Borehole Research Group, Lamont-Doherty Earth Observatory, Palisades, NY 10964.

ODP, 1992. "Revised Guidelines for Development of Third-Party Tools", JOIDES Journal. Vol. 18, No. 3, p. 37. The equivalent pamphlet, Guide to Third-Party Tools, is available from JOI, Inc., 1755 Massachusetts Avenue NW, Washington, DC 20036-2102.

\section{FIGURE CAPTION}

Temperature logs made in the VC-2B corehole, Valles Caldera, NM, USA. The log of May, 1990 was made shortly after circulation of drilling fluids was stopped, and it shows permeable zones of lost circulation that were candidates for fluid-sampling experiments. The insert illustrates the liquid-vapor interface after the fluid level in the hole had dropped to an equilibrium level, (Lysne, 1991).

\section{TABLE 1. Tools Commonly Used to Measure Porosity.}

\begin{tabular}{lllll}
\hline Tool & $\begin{array}{l}\text { Underlying } \\
\text { Physics }\end{array}$ & $\begin{array}{l}\text { Bulk Material } \\
\text { Model }\end{array}$ & $\begin{array}{l}\text { Primary } \\
\text { Property }\end{array}$ & $\begin{array}{l}\text { Interpretive } \\
\text { Model }\end{array}$ \\
\hline Resistivity & $\begin{array}{l}\text { Maxwell's } \\
\text { Eqs. }\end{array}$ & Ohm's Law & resistivtiy & Archie's Law \\
Sonic & $\begin{array}{l}\text { Newton's } \\
\text { Eqs. }\end{array}$ & $\begin{array}{l}\text { Hook's Law, } \\
\text { density }\end{array}$ & $\begin{array}{l}\text { sonic } \\
\text { velocity }\end{array}$ & Wyllie's Law \\
Beutron & $\begin{array}{l}\text { Boltzmann's } \\
\text { Eq. }\end{array}$ & $\begin{array}{l}\text { elemental } \\
\text { composition of } \\
\text { matrix, Z }>1\end{array}$ & $\begin{array}{l}\text { hydrogen } \\
\text { content }\end{array}$ & $\begin{array}{l}\text { ratio, pore } \\
\text { water to } \\
\text { bound water }\end{array}$ \\
Gamma & Boltzmann's & $\begin{array}{l}\text { elemental } \\
\text { composition of } \\
\text { matrix }\end{array}$ & density & grain density \\
& & &
\end{tabular}




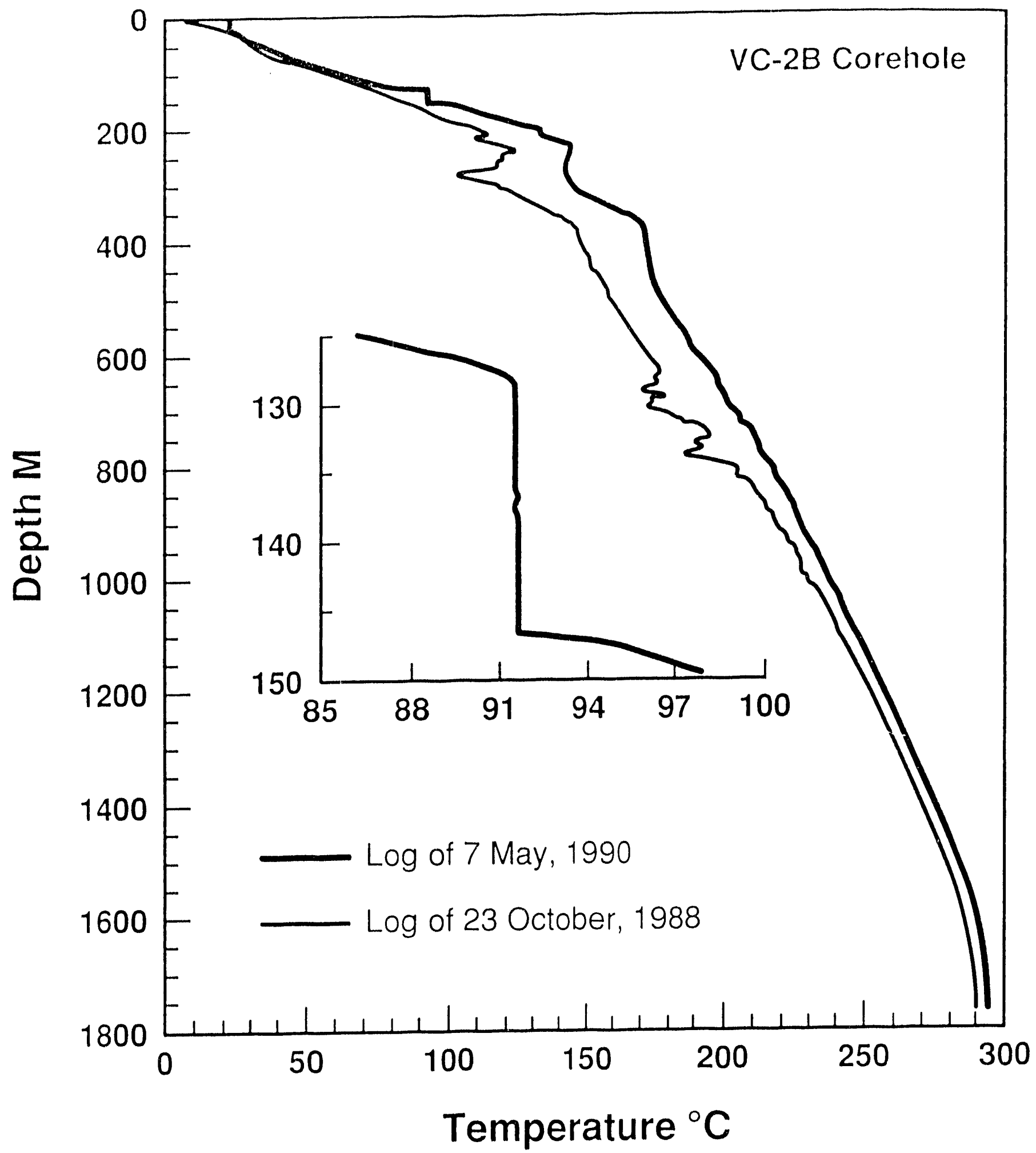

